\title{
7. INTERLABORATORY COMPARISON OF ELECTRON PROBE MICROANALYSIS OF GLASS GEOCHEMISTRY ${ }^{1}$
}

\author{
John B. Hunt, ${ }^{2}$ Peter D. Clift, ${ }^{3}$ Christian Lacasse,${ }^{4}$ Tracy L. Vallier, ${ }^{5}$ and Reinhard Werner ${ }^{6}$
}

\begin{abstract}
Tephrochronology commonly relies upon grain-discrete analysis of glass shards to reveal the subtle geochemical differences between tephras from past explosive volcanic eruptions. The use of electron probe microanalysis for this purpose is widely accepted by tephrochronologists. In addition, it is recognized widely that both precision and accuracy must be maximized, and that rigorous standardization procedures must be followed. In this paper, the performance of five electron microprobe centers used in the analysis of glass shards from Leg 152 tephras is compared, using a geochemically homogeneous obsidian secondary standard. The results reveal the compatibility of most of the participants, supporting the comparability of additional glass geochemistry presented within this volume.

In recent years the application of distal tephrochronology to stratigraphical problems in the North Atlantic Quaternary record has become increasingly common. Geochemical standardization is vitally important at an early stage in the development of tephrochronological frameworks, and it is hoped that exercises such as that presented here will encourage the production of reliable tephra geochemical data, both on Ocean Drilling Program exercises and wider afield.
\end{abstract}

\section{INTRODUCTION}

In the International Union for Quaternary Research (INQUA) Inter-Congress Committee on Tephrochronology recommendations on the geochemical analysis of tephra (Froggat, 1992), it is suggested that calibration of analytical instruments is essential and that a common set of glass standards should be available to facilitate the analysis of vitric tephras. The principal factors supporting this approach are (1) the inherent instability of glasses during electron probe microanalysis (Keller, 1981; Nielson and Sigurdsson, 1981) and the subsequent mobilization of sodium, and (2) the high precision required to justify geochemical correlations of discrete tephras (Hunt and Hill, 1993). Despite these recommendations, the publication of glass-standard analyses in association with tephra geochemical data appears relatively uncommon. Furthermore, inspection of published tephra geochemistry, as highlighted by Hunt and Hill (1993; 1994), suggests that problems of sodium mobilization remain unaddressed at a number of analytical centers, particularly with respect to North Atlantic tephrochronology. One approach to this problem is the establishment of an interlaboratory comparability program as a check on the quality of geochemical data. Although such exercises are frequently undertaken by the radiocarbon dating community (e.g., I.S.G., 1982; Baillie, 1990) and, albeit to a lesser extent, by the geochemical community (Fairbairn, 1951; Stevens and Niles, 1960; Normand et al., 1989), literature searches have revealed very limited documentation of the interlaboratory comparison of electron microprobe data (see Jarosewich et al., 1979). Such a program can serve two functions: (1) to provide further internal checks on the data quality for users of that center, and (2) with publication of data in attrib-

${ }^{1}$ Saunders, A.D., Larsen, H.C., and Wise, S.W., Jr. (Eds.), 1998. Proc. ODP, Sci. Results, 152: College Station, TX (Ocean Drilling Program).

${ }^{2}$ Center for Environmental Change and Quaternary Research, Department of Geography and Geology, Cheltenham and Gloucester College of Higher Education, Francis Close Hall, Cheltenham, GL50 4AZ,United Kingdom. jhunt@chelt.ac.uk

${ }^{3}$ Ocean Drilling Program, 1000 Discovery Drive, Texas A\&M University Research Park, College Station, TX 77845-9547, U.S.A. (Present address: Scripps Institute of Oceanography, University of California at San Diego, La Jolla, CA 92093-0215, U.S.A.)

${ }^{4}$ Graduate School of Oceanography, University of Rhode Island, South Ferry Road, South Laboratory, Narragansett, RI 02882-1197, U.S.A.

${ }^{5}$ U.S. Geological Survey, 345 Middlefield Road, Menlo Park, CA 94025, U.S.A

${ }^{6}$ GEOMAR, Research Centre for Marine Geosciences, Wischofstrasse 1-3, Gebäude 4, D-24148 Kiel 14, Federal Republic of Germany. utable form, to provide a check on the likely quality of previously published geochemical data for the wider geological (tephra) community.

In this paper we present the results of an interlaboratory comparison program that was conducted following Leg 152. Data were supplied by electron microprobe laboratories at Brown University, Rhode Island; Edinburgh University; the USGS at Menlo Park; GEOMAR at Kiel; and Texas A\&M University, College Station. In undertaking an interlaboratory comparability program the vital first step is to ensure the geochemical homogeneity of the potential standard. A commonly used standard (Froggat, 1992) is a comendite obsidian from Kenya, KN-18 (Nielson and Sigurdsson, 1981). This study is based on a similar material, namely a sample of the Cannetto Lami obsidian from the Lipari (Aeolian Islands) $40 \mathrm{~km}$ north of Sicily. This obsidian has served as an extremely useful secondary standard, and its petrography is described by Hunt and Hill (1996). While a number of well documented glass standards are available, the Lipari obsidian is particularly appropriate because it contains a wide range of the principal major elements found in vitric tephras, and initial results suggest that it is less susceptible to sodium mobility than some other standards (e.g., KN-18).

\section{THE LIPARI OBSIDIAN}

The calc-alkaline island arc volcanism associated with the Aeolian Islands has been producing extensive lava flows and pyroclastic deposits from about $100 \mathrm{ka}$ to the present day (Villari, 1980). The island of Lipari is the largest in this archipelago and is noted for its abundant obsidian lava flows. On the northeast of the island, several flows that relate to the final phase (period IV) of volcanism on Lipari can be found (Pichler, 1980). One of these flows, the Cannetto Lami lava, is the source of the obsidian used in this study. This lava is estimated to be 8 ka (R.S.J. Sparks, pers. comm., 1991), in agreement with the dates of $8300 \pm 860$ BP (Bigazzi and Bonadonna, 1973; Wagner et al., 1976) obtained from the "older obsidianic lavas" of nearby Mount Pilato.

\section{Geochemical Homogeneity of the Lipari Obsidian}

The interlaboratory program described in this paper is based largely on the assumption that the obsidian is geochemically homo-

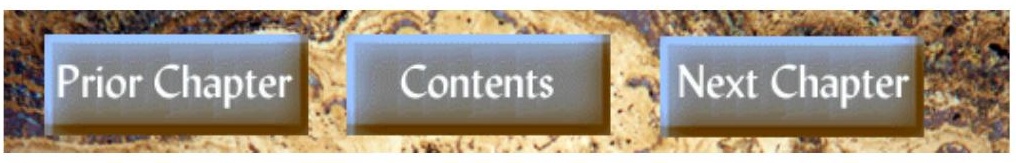


geneous on a micrometer scale. For the purposes of analysis, the presence of occasional microcrystalline phases does not negate this assumption as they are readily visible through the electron microprobe optics, and their analysis can be avoided easily. Backscattered electron images of random obsidian fragments sustain this assumption because there are no apparent variations in mean atomic number. Inspection of additional obsidian, in both backscattered electron and element mapping ( $\mathrm{Si}, \mathrm{Al}, \mathrm{Fe}_{\text {total oxides }}, \mathrm{Mn}, \mathrm{Mg}, \mathrm{Ca}, \mathrm{Na}$, and $\mathrm{K}$ ) modes, corroborates this conclusion. However, to confirm geochemical homogeneity, the obsidian was analyzed by quantitative wavelength dispersive spectrometry (WDS) using the analytical strategy described below.

\section{Initial Quantitative Test}

Two polished probe sections were prepared from orthogonal slices $(\sim 2.5 \mathrm{~cm} \times 1.5 \mathrm{~cm})$ cut from a block of the Lipari obsidian. The orientation of these sections permitted a 3-D assessment of spatial variations in the geochemical composition of the obsidian. The sections were analyzed on the Cameca Camebax (see Table 1 for operating conditions) at the Edinburgh electron microprobe center. These data were obtained by an automated run, and subsequently some data were removed where sample surface roughness or the presence of local heterogeneities had obviously resulted in a poor individual analysis. The Camebax data include 184 analyses, which serve as a comprehensive base on which to perform a statistical analysis.

Calculation of the Homogeneity Index (Boyd et al., 1967) for each element reveals that the Lipari obsidian may be regarded as homogeneous in all elements analyzed $\left(\mathrm{H}_{\max }=1.13\right)$. Values of $\mathrm{H}$ greater than three are taken to be indicative of chemical inhomogeneity, and indices up to 1.2 are quoted for the standards used in the Boyd et al. (1967) study. The H index is favored over the K-factor of Potts et al. (1983), which is only applicable universally if the analysis routine is constructed such that elements, in similar proportions, are analyzed to generate the same number of raw counts. This approach is unreasonable because low abundance elements would require impracticably long analysis times, which would, in analysis of glasses, result in sample damage and loss of accuracy (Froggat, 1983).

\section{Geochemical Composition of the Lipari Obsidian}

Whereas the large number of data points acquired by electron microprobe traverses confirm homogeneity of the sample and precision of probe data, independent analysis of the sample by other techniques is required to characterize probe accuracy. This has been achieved by two further methods: (1) X-ray fluorescence analysis (XRF), and (2) wet chemistry determinations. In addition, manual electron probe microanalysis was performed on a different instrument at Edinburgh.

\section{XRF Analysis}

A sample of the Lipari obsidian (from the same block as the original orthogonal probe sections) was prepared for XRF analysis. The obsidian was ground to a fine powder, $1 \mathrm{~g}$ of which was mixed with $5 \mathrm{~g}$ of borate flux, and heated in a furnace at $1100^{\circ} \mathrm{C}$. The samples, prepared as fused beads, were analyzed on a Philips PW 1480 automatic XRF spectrometer and corrections applied for mass absorption. A range of international reference materials was used to construct the calibration lines for individual elements. These reference materials (from the USGS and CRPG) included: RGM-1 (USGS rhyolite), ALI (albite), AGV-1 (USGS andesite), BE-N (basalt), BIR-1 (Icelandic basalt), and PCC-1 (USGS peridotite). The results of the Edinburgh $\mathrm{XRF}$ analyses are extremely close $\left(\sigma_{\max }\left(\mathrm{Al}_{2} \mathrm{O}_{3}\right)=0.23\right)$ to the results provided by independent XRF analysis at a Bristol, as determined for a sample from the same obsidian block (see Table 2).

\section{Wet Chemistry Analysis}

Determination of the alkali metals in glasses and feldspars has proved problematic both by XRF analysis and by electron microprobe methods (e.g., Froggat, 1983). As a check on the accuracy of the electron probe in analyzing potassium, and more particularly, sodium, wet chemical determinations were conducted. Calibration samples from sodium and potassium sulfates were prepared, ground, and dried at $500^{\circ} \mathrm{C}$ prior to weighing. Calibration samples were prepared as mixed and matched solutions (with sodium and potassium in similar proportions to those expected in the obsidian). The USGS granite, G1 (see Flanagan, 1969, 1973; Fleischer, 1969), was used as a standard to validate the Lipari results. Two techniques were used: atomic absorption (using an air/acetylene flame on a Varian Spectra AA.300) and flame photometry (using an air/propane flame on a Varian Techron AA4/5). The obsidian used in these analyses was taken from the same block as that which supplied the XRF powders (for results see Table 2).

Additional electron probe microanalysis was made of the same sections using a different instrument at Edinburgh (a Cambridge Instruments Microscan V). The data were acquired in manual mode; therefore, the local heterogeneities were avoidable, and all data from a single run are included. As calibration samples used are common to both probes, the data sets are independent in that correction processes and probe configurations have been tested.

In North Atlantic tephrochronological studies geochemical correlations have often been made by graphical (Harker and triangular plots) comparison alone. Although this method is adequate in the most part, it lacks the rigorous approach to correlation that is possible through the application of similarity coefficients (Borchardt et al., 1972; Hunt and Hill, 1993; Lacasse et al., 1995) and discriminant function analysis (Stokes et al., 1992). For this reason we have applied the similarity coefficient (s.c.) to the results from the homogeneity assessment exercise and the interlaboratory comparability program. The similarity coefficient is a numerical tool given by:

$$
d_{(\mathrm{A} . \mathrm{B})}=\frac{\sum_{i=1}^{n} R_{i}}{n}
$$

where:

$d_{\text {(A.B) }}=d_{(\mathrm{B} . \mathrm{A})}=$ similarity coefficient for comparison between sample A and sample B,

Table 1. Operating conditions for the electron microprobe centers participating in the interlaboratory comparison program.

\begin{tabular}{|c|c|c|c|c|c|c|c|}
\hline Laboratory & $\begin{array}{l}\text { Laboratory } \\
\text { identifier }\end{array}$ & Spectrometry & $\begin{array}{l}\text { Beam current } \\
(\mathrm{nA})\end{array}$ & $\begin{array}{l}\text { Accelerating } \\
\text { voltage } \\
(\mathrm{kV})\end{array}$ & $\begin{array}{l}\text { Beam size } \\
\qquad(\mu \mathrm{m})\end{array}$ & $\begin{array}{l}\text { Number of } \\
\text { analyses }\end{array}$ & $\begin{array}{l}\text { Correction } \\
\text { procedure }\end{array}$ \\
\hline Edinburgh (Camabax) & 1 & W.D. & 10 & 20 & 10 & 184 & $\phi \rho z(\mathrm{PAP})$ \\
\hline Edinburgh $(\mathrm{MkV})$ & 2 & W.D. & 15 & 20 & d.f. & 20 & ZAF \\
\hline GEOMAR, Kiel & 3 & W.D. & 10 & 15 & R.A. & 30 & PAP \\
\hline Texas A\&M & 4 & W.D. & 10 & 20 & $\mathrm{n} / \mathrm{a}$ & 50 & $\mathrm{n} / \mathrm{a}$ \\
\hline USGS & 5 & W.D. & $\mathrm{n} / \mathrm{a}$ & $\mathrm{n} / \mathrm{a}$ & $\mathrm{n} / \mathrm{a}$ & 3 & $\mathrm{n} / \mathrm{a}$ \\
\hline Brown University, R.I. & 6 & W.D. & 10 & 15 & 10 & 20 & $\mathrm{n} / \mathrm{a}$ \\
\hline
\end{tabular}

Notes: W.D. = wavelength dispersive; d.f. = defocussed; R.A. = rastered beam; n/a = not made available; R.I. = Rhode Island; USGS = United States Geological Survey. 
Table 2. Summary data for all the laboratories participating in the international electron microprobe comparison program.

\begin{tabular}{|c|c|c|c|c|c|c|c|c|c|}
\hline $\begin{array}{l}\text { Laboratory } \\
\text { idenitifier }\end{array}$ & Statistic & $\mathrm{SiO}_{2}$ & $\mathrm{Na}_{2} \mathrm{O}$ & $\mathrm{K}_{2} \mathrm{O}$ & $\mathrm{FeO}^{*}$ & $\mathrm{MgO}$ & $\mathrm{Al}_{2} \mathrm{O}_{3}$ & $\mathrm{CaO}$ & $\mathrm{MnO}$ \\
\hline \multirow[t]{4}{*}{ Lab 1} & $\min$. & 73.93 & 3.73 & 4.99 & 1.18 & 0.02 & 12.70 & 0.69 & 0.03 \\
\hline & $\max$ & 74.82 & 4.07 & 5.48 & 1.65 & 0.08 & 13.03 & 0.79 & 0.70 \\
\hline & mean & 74.35 & 3.93 & 5.12 & 1.51 & 0.05 & 12.87 & 0.74 & 0.08 \\
\hline & $2 \sigma$ & 0.34 & 0.12 & 0.1 & 0.1 & 0.02 & 0.12 & 0.04 & 0.10 \\
\hline \multirow[t]{4}{*}{ Lab 2} & $\min$. & 73.85 & 3.89 & 5.02 & 1.34 & 0.03 & 12.69 & 0.71 & 0.02 \\
\hline & max. & 71.85 & 4.27 & 5.31 & 1.64 & 0.08 & 13.33 & 0.81 & 0.11 \\
\hline & mean & 74.27 & 4.07 & 5.17 & 1.49 & 0.05 & 13.00 & 0.74 & 0.07 \\
\hline & $2 \sigma$ & 0.60 & 0.20 & 0.16 & 0.16 & 0.12 & 0.28 & 0.06 & 0.04 \\
\hline \multirow[t]{4}{*}{ Lab 3} & $\min$. & 73.50 & 3.67 & 4.94 & 1.27 & 0.02 & 13.26 & 0.68 & 0.00 \\
\hline & $\max$ & 74.58 & 3.99 & 5.23 & 1.67 & 0.06 & 13.65 & 0.80 & 0.11 \\
\hline & mean & 74.08 & 3.88 & 5.08 & 1.47 & 0.04 & 13.48 & 0.74 & 0.06 \\
\hline & $2 \sigma$ & 0.52 & 0.13 & 0.01 & 0.18 & 0.02 & 0.19 & 0.05 & 0.05 \\
\hline \multirow[t]{4}{*}{ Lab 4} & $\min$. & 73.59 & 3.72 & 5.05 & 1.33 & 0.01 & 12.97 & 0.66 & 0.00 \\
\hline & $\max$ & 74.66 & 3.93 & 5.33 & 1.67 & 0.08 & 13.32 & 0.78 & 0.14 \\
\hline & mean & 74.07 & 3.81 & 5.17 & 1.50 & 0.04 & 13.14 & 0.72 & 0.06 \\
\hline & $2 \sigma$ & 0.46 & 0.10 & 0.12 & 0.13 & 0.02 & 0.15 & 0.05 & 0.06 \\
\hline \multirow[t]{4}{*}{ Lab 5} & min. & 75.08 & 2.24 & 5.03 & 1.56 & 0.03 & 13.33 & 0.75 & 0.06 \\
\hline & $\max$ & 75.62 & 2.49 & 5.05 & 1.67 & 0.05 & 13.67 & 0.78 & 0.07 \\
\hline & mean & 75.36 & 2.39 & 5.05 & 1.61 & 0.04 & 13.55 & 0.77 & 0.07 \\
\hline & $2 \sigma$ & 0.53 & 0.27 & 0.02 & 0.11 & 0.03 & 0.39 & 0.03 & 0.01 \\
\hline \multirow[t]{2}{*}{ Lab 6} & mean & 73.87 & 4.19 & 5.04 & 1.53 & 0.05 & 12.83 & 0.73 & 0.07 \\
\hline & $2 \sigma$ & 0.68 & 0.44 & 0.26 & 0.18 & 0.04 & 0.16 & 0.06 & 0.10 \\
\hline Lab 7 & $\min$. & 73.72 & 4.06 & 5.06 & 1.75 & 0.03 & 13.04 & 0.76 & 0.06 \\
\hline Lab 8 & $\min$ & 74.03 & 4.06 & 5.18 & 1.73 & 0.00 & 12.72 & 0.72 & 0.08 \\
\hline \multirow[t]{4}{*}{ Lab 9} & $\min$. & & 3.78 & 4.50 & & & & & \\
\hline & $\max$ & & 4.34 & 5.33 & & & & & \\
\hline & mean & & 4.06 & 4.99 & & & & & \\
\hline & $2 \sigma$ & & 0.15 & 0.25 & & & & & \\
\hline \multirow[t]{4}{*}{ Lab 10} & $\min$. & & 3.55 & 4.86 & & & & & \\
\hline & $\max$ & & 4.12 & 5.19 & & & & & \\
\hline & mean & & 3.89 & 5.01 & & & & & \\
\hline & $2 \sigma$ & & 0.17 & 0.13 & & & & & \\
\hline
\end{tabular}

Notes: A number of additional elements have been determined in some data sets (e.g., F, Cl, S, Ti) but have been excluded as they are not common to all. FeO* indicates total iron $\left(\mathrm{Fe}_{2} \mathrm{O}_{3}+\mathrm{FeO}\right) ; \sigma=$ standard deviation; Labs 7 and 8 are XRF analyses.

Table 3. Similarity coefficients for the analyses of the sodium content of the Lipari obsidian.

\begin{tabular}{lllllll}
\hline \multicolumn{1}{c}{ Analytical method } & Identifier & Lab 1 & Lab 2 & Lab 7 & Wet ch. 1 Wet ch. 2 \\
\hline EPMA & Lab 1 & 1 & & & \\
EPMA & Lab 2 & 0.97 & 1 & & \\
XRF & Lab 7 & 0.97 & 1 & 1 & & \\
Wet chemical analysis & Wet ch. 1 & 0.97 & 1 & 1 & 1 & \\
Wet chemical analysis & Wet ch. 2 & 0.99 & 0.96 & 0.96 & 0.96 & 1 \\
\hline
\end{tabular}

Notes: Mean values of EPMA and wet chemical data, and a single XRF analysis, were used in the calculation of the coefficient. In all cases s.c. > 0.96 .

$i=$ element number,

$n=$ number of elements in calculation,

$R_{i}=\mathrm{X}_{i \mathrm{~A}} / \mathrm{X}_{i \mathrm{~B}}\left(\right.$ if $\left.\mathrm{X}_{i \mathrm{~B}}>\mathrm{X}_{i \mathrm{~A}}\right)$,

$R_{i}=\mathrm{X}_{i \mathrm{~B}} / \mathrm{X}_{i \mathrm{~A}}\left(\right.$ if $\left.\mathrm{X}_{i \mathrm{~A}}>\mathrm{X}_{i \mathrm{~B}}\right)$,

$\mathrm{X}_{i \mathrm{~A}}=$ concentration of element $i$ in sample $\mathrm{A}$, and

$\mathrm{X}_{i \mathrm{~B}}=$ concentration of element $i$ in sample $\mathrm{B}$ (from Borchardt et al., 1972).

Data gathered by these methods are extremely encouraging and indicate that the Lipari obsidian should serve as an excellent secondary standard for the analysis of vitric tephras. Summary electron probe data and statistics, obtained for both the Camebax (Lab 1) and the Microscan V (Lab 2), are presented within Table 2. Comparison of these data indicates that both probes are consistent. Indeed the similarity coefficient (see Table 3) outlined by Borchardt et al. (1972) gives a near perfect agreement $($ s.c. $=0.99)$, with the largest difference $(0.14 \%$ absolute) due to sodium, probably resulting from the longer exposure time on the Camebax as the consequence of an inability to blank the beam between count acquisition. However, the additional effects of small differences in beam size cannot be discounted.

The XRF data (Table 2) are in good agreement with both electron probe data sets. The largest percentage discrepancy arises with the comparison of the iron determinations and is almost certainly due to the inclusion of the pyrite and oxide microcrystallites in bulk XRF analysis.

The general agreement of the two techniques is illustrated by the similarity coefficients (Table 3 ) between the XRF and probe data

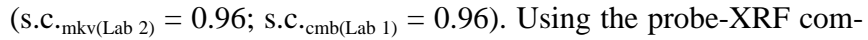
parison enables the establishment of a threshold similarity coefficient value for the Lipari obsidian. The minimum value for the similarity coefficient between the probe data established in the homogeneity assessment and probe data from other laboratories should therefore not be lower than s.c. $=0.96$ (Hunt and Hill, 1996).

Data from the "wet" chemical determination of sodium and potassium further confirm the composition of the Lipari obsidian. In total eight determinations for sodium and six for potassium were obtained. Taking mean values, the similarity coefficients for sodium and potassium exceed s.c. $=0.97$ for all combinations of Edinburgh wet chemistry, XRF, and electron probe data (Table 3).

\section{THE INTERLABORATORY COMPARABILITY PROGRAM}

The homogeneous Lipari obsidian was distributed to all of the participating laboratories, as fragments of the original sectioned block. An analytical protocol was not circulated, although it was suggested that $\sim 20$ analyses would form a meaningful contribution. To avoid biasing the results, the contributing laboratories were requested to prepare and analyze the obsidian using the same conditions that would have been normally adopted for the analysis of vitric tephras. The obsidian analyses from these laboratories were therefore performed under the same conditions used in the acquisition of their published tephra data, and the reliability of the obsidian data is con- 
sequently linked directly to the reliability of such published tephra data.

\section{Results of the Comparability Program}

Representative geochemical data from the interlaboratory analysis of the obsidian are listed in the Appendix. For brevity, these data are referred to by source (Labs 1-6), and operating conditions and summary data are presented, respectively, in Tables 1 and 2. A total of 288 separate analyses were performed on the obsidian, collectively representing 2617 discrete data points. This database provides a robust foundation for the statistical comparison of the performance of the participating laboratories. Mean data values for each data set have been used as the basis for discussion throughout the remainder of this paper, and $2 \sigma$ values are provided for each data set in Table 2.

Calculation of variance from the mean compositional data supplied by each laboratory (Table 4) indicates that sodium and silicon together account for $\sim 90 \%$ of all the variability between laboratories. The data suggest that these elements are the most appropriate for investigation in the interlaboratory comparison program and that together they form a reliable basis for categorizing and discriminating between the data sets.

Principally on the basis of the sodium and silicon assays (Fig. 1), the electron probe data can be categorized broadly into two groups: (1) the concordant data - those whose mean and range correspond with the wet chemistry and XRF assays, and are in agreement with the Homogeneity Index as discussed earlier; and (2) the discordant data-those whose accuracy is not in accord with data from group 1.

Data sets are discussed within this context although reference should be made to the summary data (Table 2) and to the interlaboratory similarity coefficients calculated from all major element data (Table 5) for all laboratories. A value of s.c. $=0.95$ is taken as the division between correlation and noncorrelation. In the following discussions the sodium and silicon means and $2 \sigma$ ranges for each laboratory (Table 2) will also be used as a means of performance assessment.

\section{Group 1: the Concordant Data}

Data from Laboratories 1 and 2 have already been discussed with respect to the homogeneity of the obsidian and their comparison with the XRF and wet chemistry data.

\section{Laboratory 3}

This data set was acquired by WDS at a beam current of $10 \mathrm{nA}$, and an accelerating voltage of $15 \mathrm{kV}$. The range of the data set overlaps with data from Labs 1 and 2 and the XRF analyses, for both sodium and silicon, with good agreement between the mean and $2 \sigma$ values. The s.c. values between these data and those from Labs 1 and 2 are 0.98 and 0.97 , respectively.

\section{Laboratory 4}

Data were acquired by WDS at a beam current of $10 \mathrm{nA}$, and an accelerating voltage of $20 \mathrm{kV}$. As with $\mathrm{Lab} 3$, the range of the data set overlaps with data from Labs 1 and 2 and the XRF analyses, for both sodium and silicon, with good agreement between the mean and $2 \sigma$ values. The s.c. values between these data and those from Labs 1 and 2 are both 0.98 .

\section{Laboratory 6}

Data were acquired by WDS at a beam current of $10 \mathrm{nA}$ and an accelerating voltage of $15 \mathrm{kV}$. The sodium field indicates slightly higher values in comparison with Labs 1 and 2, whereas silicon is marginally less abundant. Nevertheless, the range of the data set overlaps with data from Labs 1 and 2 and the XRF analyses, for both sodium and silicon, with good agreement between the mean and $2 \sigma$ values. The s.c. values between these data and those from Labs 1 and
Table 4. Percentage contributions made by each major/minor element toward the variability of the interlaboratory data set.

\begin{tabular}{cccccccc}
\hline $\mathrm{SiO}_{2}$ & $\mathrm{Na}_{2} \mathrm{O}$ & $\mathrm{K}_{2} \mathrm{O}$ & $\mathrm{FeO}^{*}$ & $\mathrm{MgO}$ & $\mathrm{Al}_{2} \mathrm{O}_{3}$ & $\mathrm{CaO}$ & $\mathrm{MnO}$ \\
\hline 34.40 & 53.44 & 0.37 & 0.24 & 0.04 & 11.46 & 0.04 & 0.01 \\
\hline
\end{tabular}

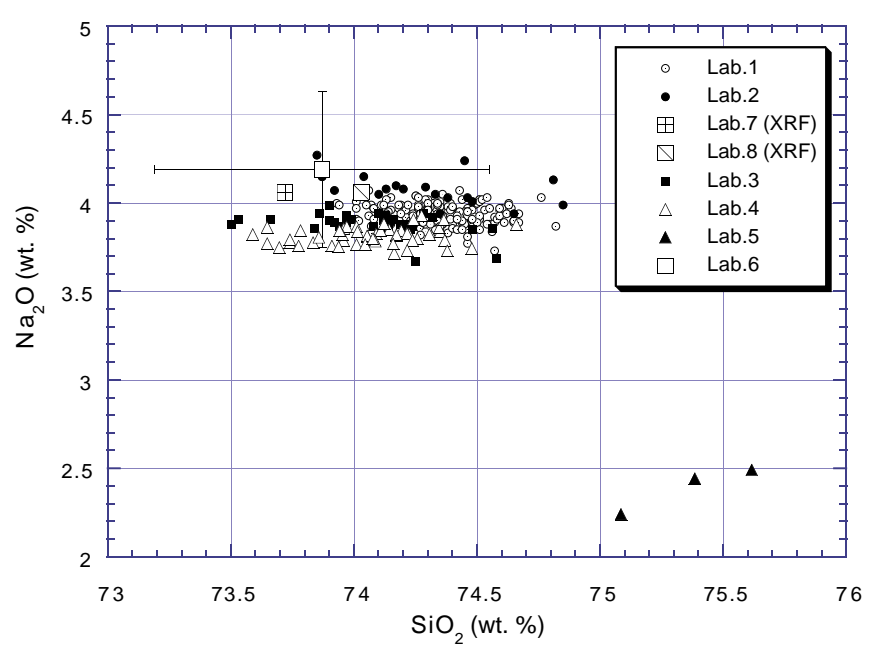

Figure 1. Data from the analysis of the Lipari obsidian as determined in this interlaboratory exercise. The XRF and probe data are all concordant, with the exception of Lab 5. This data set is characterized by low $\mathrm{Na}_{2} \mathrm{O}$ and high $\mathrm{SiO}_{2}$. This behavior is commonly associated with electron-beam-induced sodium mobility and its consequent "loss" from the determined assay.

Table 5. Similarity coefficients based on mean values for all electron microprobe major element data calculated by the methods outlined in Borchardt et al. (1972).

\begin{tabular}{lcccccc}
\hline & Lab 1 & Lab 2 & Lab 3 & Lab 4 & Lab 5 & Lab 6 \\
\hline Lab 1 & 1 & & & & & \\
Lab 2 & 0.99 & 1 & & & & \\
Lab 3 & 0.98 & 0.97 & 1 & & & \\
Lab 4 & 0.98 & 0.98 & 0.98 & 1 & & \\
Lab 5 & 0.90 & 0.91 & 0.91 & 0.91 & 1 & \\
Lab 6 & 0.98 & 0.98 & 0.97 & 0.97 & 0.90 & 1 \\
\hline
\end{tabular}

Note: Of these data sets only that from Laboratory 5 falls below the threshold similarity coefficient (s.c. $=0.96$ ) for comparability with the homogeneity assessment data.

2 are both 0.98 . Sodium loss was minimized in this laboratory by using a beam defocussed to $10 \mu \mathrm{m}$ and by counting at regular $(2 \mathrm{~s})$ time intervals. The sodium content was determined by extrapolation of the resultant decay curve back to count-initiation.

\section{Group 2: the Discordant Data}

Only one laboratory has provided data that deviates from the concordant cluster.

\section{Laboratory 5}

Data from this laboratory are generally of good precision $\left(\sigma_{\max \left(\mathrm{SiO}_{2}\right)}=0.27\right)$. However, discrepancies arise between this data set and those in Group 1, particularly with respect to sodium, silicon, and (to a lesser extent) aluminum. The sodium is consistently lower than expected, and this is accompanied by high silicon and aluminum values. Similarity coefficients relating these data to probe Labs 1 and 2, and the XRF Labs 7 and 8, give values of s.c. $=0.90-0.91$ and s.c. $=0.90$, respectively. These data indicate the over-representation of high abundance elements associated with sodium loss. 


\section{INTERPRETATIONS}

The data are discussed in more detail here, in an attempt to explain any discrepancies. Failure to do so would weaken, at least in part, the case for the homogeneity of all the Lipari samples. Furthermore, without such explanation, the rejection of one data set over another could result in the program being viewed perhaps as Edinburgh biased. The data sets are discussed in the order presented in the previous section. Graphical comparisons of sodium and silicon data are presented alongside data from an earlier and similar interlaboratory program undertaken in northern Europe. Gross errors in the determination of sodium and silicon, such as were reported by Hunt and Hill (1996), are apparent in this study (cf. Fig. 2).

Data from Lab 5 clearly show the influence of sodium mobilization and silicon over-representation (Table 2). The data, however, are internally consistent, and sodium displays reasonable precision, $2 \sigma_{\mathrm{Na}_{2} \mathrm{O}}=0.27$ (Fig. 1; Table 2), despite the small sample-size ( $\mathrm{n}=$ 3 ). These data fall in the same field as that occupied by data set "A" from the European exercise (Hunt and Hill, 1996), which was shown to suffer from the same problems in sodium determination. On average the sodium values from Lab 5 are only $60 \%$ of the mean value calculated from the remaining laboratories, and silica differs on average by $1.23 \%$ (absolute). Caution should be exercised if data from this laboratory are used in tephrochronological correlations. Such studies require extremely precise and accurate determinations as geochemical differences between discrete tephras can be very small (see Hunt and Hill, 1993). Petrologic studies generally do not require such precision, and these data therefore can be used with more confidence. In this instance, as silica content is high, all data fall on same field (rhyolite) of the TAS plot (Le Maitre, 1989) despite the low sodium value for Lab 5.

All remaining data are consistent, although it is interesting to examine the range and value of the determinations of sodium and silica from Lab 6. These data have been normalized to the composition of the Smithsonian obsidian standard (KN-18), and sodium content extrapolated to analyses time, $\mathrm{T}_{\mathrm{A}}=0 \mathrm{~s}$. Sodium values overlap with, but are marginally higher than, the remaining probe and XRF data. The differences between the data sets are not significant, however.

\section{Potential Influence of the ZAF and PAP $(\phi \rho z)$ Correction Procedures}

General analytical discrepancies cannot always be attributed to instrumental failure or operator error because the different correction procedures available to the electron microprobe analyst are also potential causes of discrepancy. Correction procedures used in the production of electron microprobe data are designed to take account of the three matrix effects: atomic number (Z), X-ray absorption (A), and secondary fluorescence $(\mathrm{F})$. These correction procedures are therefore commonly referred to as the ZAF correction (Sweatman and Long, 1969; Reed, 1975; Potts, 1987). In more recent years, the traditional ZAF approach has been refined, largely through the utilization of more powerful computing techniques (Pouchou and Pichoir, 1991, and references therein). To test the general comparability of the two approaches the raw count data from the Lipari obsidian (used in the calculation of the Lab 1 data set) were processed by both ZAF and $\phi \rho z$ (PAP) software. The results from this exercise are shown in Figure 3. In all cases, the ZAF data are lower by $\sim 1 \%$ (absolute). Although this difference is not large and on its own may not be of direct tephrological significance, it clearly can be a contributory cause of analytical mismatches.

\section{CONCLUSIONS}

The data in this paper relate to the establishment of an international interlaboratory electron microprobe comparison program. The pro-

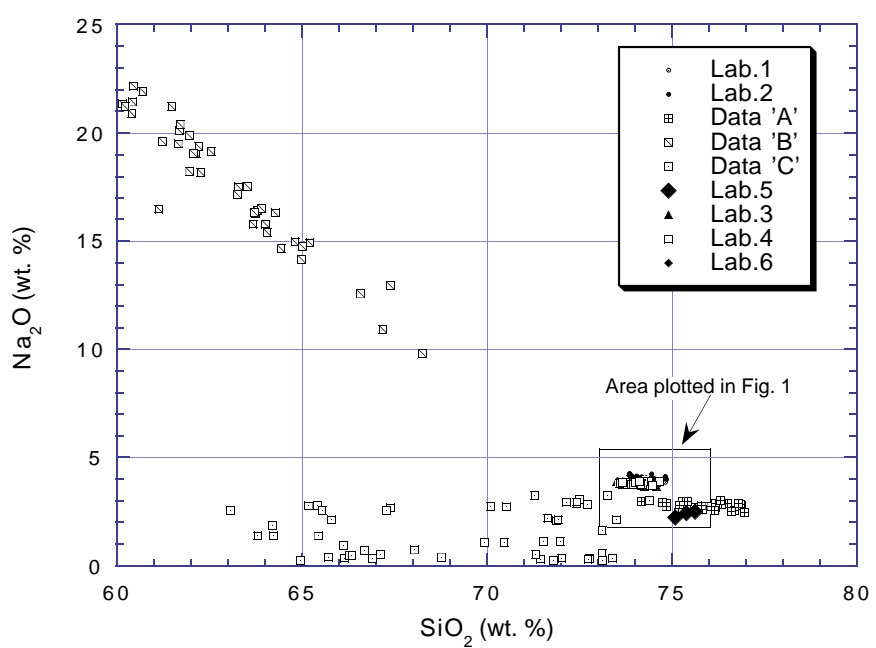

Figure 2. Data from this exercise (within box) compared with data from a previous European exercise (Hunt and Hill, 1996). The gross errors illustrated by the earlier data sets ("B" and "C") are not apparent in this study. Data from Lab 5 appear to suffer from the same problem as do the data in "A." Data "B" appear to suffer from sodium enhancement and silica underrepresentation. This may be due, in part, to charging and sodium "suck-in" as a result of beam-induced charging (see Hunt and Hill, 1996). These data were obtained from a sample that was not coated with a conductive film.

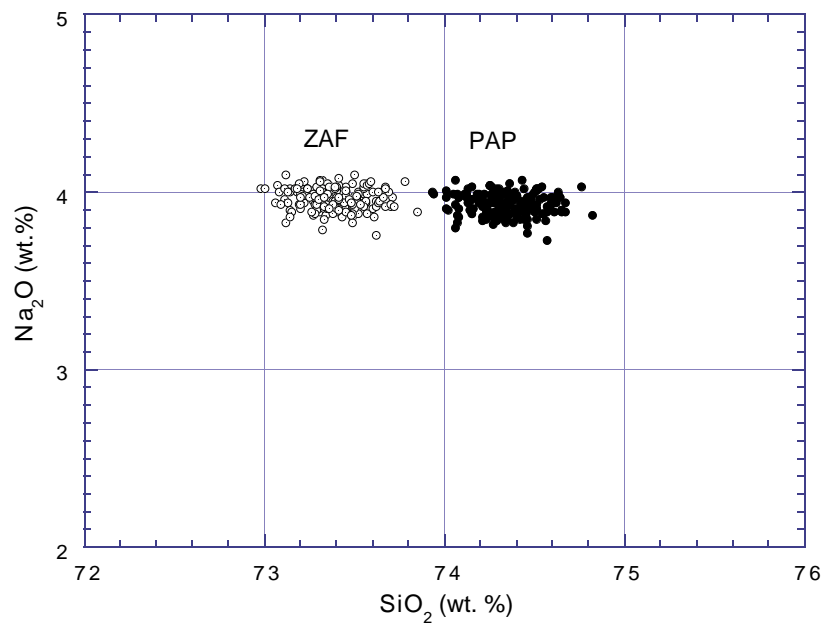

Figure 3. Data from Lab 1. Two correction procedures yield significantly different results, particularly with respect to silica. The use of different correction procedures may result in problems in tephrochronological studies where high accuracy and precision are required.

gram was devised to monitor the performance of a number of the probe centers analyzing tephras from Ocean Drilling Program (ODP) Leg 152, and to indicate the source of any analytical problems, and to assess the comparability of glass shard geochemistry in this volume. The results of the program were highly encouraging, more so than the results outlined in Hunt and Hill (1996). A number of conclusions emerge from this program, and are listed below.

1. An important secondary standard, in this case the Lipari obsidian, can be used reliably for monitoring the precision and reproducibility of the electron microprobe analyses obtained from (tephra) glass.

2. Out of the six probes (at five laboratories), all but one produced results of sufficient precision and accuracy to be used in tephrochronological correlation work. 
3. The variability of the entire data set is explained largely by $\mathrm{Na}_{2} \mathrm{O}\left(53.4 \%\right.$ of variance) and $\mathrm{SiO}_{2}$ (34.4\% of variance); this variance is attributable principally to the data supplied from one laboratory and is not a function of the obsidian, as demonstrated by the homogeneity exercise.

4. Only one of the data sets (Lab 5) appears to have suffered from the most commonly expected source of error (i.e., the phenomenon of sodium mobilization).

5. The use of different correction procedures during data processing may cause small geochemical differences that could be attributed to different chemical signatures.

6. (See recommendation 5: Froggat, 1992) The reliability of published tephra geochemical data can be gauged by the wider tephra community, only by the inclusion of representative geochemical analyses of a secondary glass standard, acquired during the same analytical session in which the tephra itself was analyzed. At the third U.K. tephra meeting (held in Cheltenham, 1994), the U.K. tephrochronology community agreed to a publishing protocol using the Lipari obsidian as a secondary standard. A similar policy was underlined at the Edinburgh annual meeting of the U.K. Quaternary Research Association in 1995.

\section{ACKNOWLEDGMENTS}

Our gratitude is extended to Prof. Steven Sparks for providing the Lipari obsidian and initial XRF data, to Gigi Delgado, and to Dr. P.J. Potts and an anonymous reviewer for constructive comments on and reviews of this paper.

\section{REFERENCES}

Baillie, M., 1990. Checking back on an assemblage of published radiocarbon dates. Radiocarbon, 32:361-366.

Bigazzi, G., and Bonadonna, F., 1973. Fission track dating of the obsidian of Lipari Island (Italy). Nature, 242:322-323.

Borchardt, G.A., Aruscavage, P.J., and Millard, H.T., Jr., 1972. Correlation of the Bishop ash, a Pleistocene marker bed, using instrumental neutron activation analysis. J. Sediment. Petrol., 42:301-306.

Boyd, F.R., Finger, L.W., and Chayes, F., 1967. Computer reduction of electron-probe data. Yearbook-Carnegie Inst. Washington, 67:210-215.

Fairbairn, H.W., 1951. A cooperative investigation of precision and accuracy in chemical, spectrochemical and modal analysis of silicate rocks. U.S. Geol. Surv. Bull., 980:1-71.

Flanagan, F.J., 1969. U.S. Geological survey standards, II. First data for the new U.S.G.S. rocks. Geochim. Cosmochim. Acta, 33:81-120.

, 1973. 1972 Values for international geochemical reference samples. Geochim. Cosmochim. Acta, 37:1189-1200.

Fleischer, M., 1969. U.S. Geological survey standards, I. Additional data on rocks G-1 and W-1, 1965-1967. Geochim. Cosmochim. Acta, 33:65-79.

Froggat, P.C., 1983. Toward a comprehensive Upper Quaternary tephra and ignimbrite stratigraphy in New Zealand using electron microprobe analysis of glass shards. Quat. Res., 19:188-200.
1992. Standardization of the chemical analysis of tephra deposits: report of the ICCT working group. Quat. Int., 13/14:93-96.

Hunt, J.B., and Hill, P.G., 1993. Tephra geochemistry: a discussion of some persistent analytical problems. The Holocene, 3:271-278.

, 1994. Geochemical data in tephrochronology: a reply to Bennett. Holocene, 4:436-438.

, 1996. An interlaboratory comparison of the electron probe microanalysis of glass geochemistry. Quat. Int. 35/36:229-241.

I.S.G. (International Study Group), 1982. An interlaboratory comparison of radiocarbon measurements in tree rings. Nature, 298:619-623.

Jarosewich, E., Parkes, A.S., and Wiggins, L.B., 1979. Microprobe analyses of four natural glasses and one mineral: an interlaboratory study of precision and accuracy. Smithsonian Contrib. Earth Sci., 22:53-67.

Keller, J., 1981. Quaternary tephrochronology in the Mediterranean. In Self, S., and Sparks, R.S.J. (Eds.), Tephra Studies, Dordrecht (D. Reidel), 227244.

Lacasse, C., Sigurdsson, H., Jóhannesson, H., Peterne, M., and Carey, C., 1995. The source of ash zone I in the North Atlantic. Bull. Volcanol., 57$1: 18-32$.

Le Maitre, R.W., 1989. A Classification of Igneous Rocks and Glossary of Terms: Oxford (IUGS, Blackwell).

Nielsen, C.H., and Sigurdsson, H., 1981. Quantitative methods for electron microprobe analysis of sodium in natural and synthetic glasses. Am. Mineral., 66:547-552.

Normand, M.D., Leeman, W.P., Blanchard, D.P., Fitton, J.G., and James, D., 1989. Comparison of major and trace element analyses by ICP, XRF, INAA and ID methods. Geostand. Newsl., 13:283-290.

Pichler, L., 1980. The Island of Lipari. In Villari, L. (Ed.), The Aeolian Islands: An Active Volcanic Arc in the Mediterranean Sea. Rend. Soc. Ital. Mineral. Petrol., 361:75-100.

Potts, P.J., 1987. A Handbook of Silicate Rock Analysis: Glasgow and London (Blackie).

Potts, P.J., Tindle, A.G., and Isaacs, M.C., 1983. On the precision of electron Microprobe data: a new test for the homogeneity of mineral standards. Am. Mineral., 68:1237-1242.

Pouchou, J.-L., and Pichoir, F., 1991. Quantitative analysis of homogeneous of stratified micro-volumes applying the model "PAP." In: Heinrich, K.F.J., and Newberry, D.E. (Eds.), Electron Probe Quantitation: New York (Plenum), 31-75.

Reed, S.J.B., 1975. Electron Microprobe Analysis: Cambridge (Cambridge Univ. Press).

Stevens, R.E., and Niles, W.E., 1960. Second report on a cooperative investigation of the composition of two silicate rocks. U.S. Geol. Surv. Bull., 1113:1-126

Sweatman, T.R., and Long, J.V.P., 1969. Quantitative electron-probe microanalysis of rock- forming minerals. J. Petrol., 10:332-379.

Villari, L., 1980. The Aeolian Islands: an active volcanic arc in the Mediterranean Sea. Rend. Soc. Ital. Mineral. Petrol., 36:1-195.

Wagner, G.A., Storzer, D., and Keler, J., 1976. Spaltspurendatierungen quartärer Gesteinglöser aus dem Mittelmeerraum. Neues. Jahrb. Mineral. Monatsh. Jg., 84-94.

Date of initial receipt: 30 October 1995

Date of acceptance: 16 August 1996

Ms 152SR-244 
APPENDIX

Representative Electron Microprobe Data (wt \%) from the Analysis of the Lipari Obsidian in the Participating Laboratories

\begin{tabular}{|c|c|c|c|c|c|c|c|c|c|c|c|c|c|c|c|}
\hline $\begin{array}{c}\text { Laboratory } \\
\text { identifier }\end{array}$ & $\mathrm{SiO}_{2}$ & $\mathrm{TiO}_{2}$ & $\mathrm{Al}_{2} \mathrm{O}_{3}$ & $\mathrm{FeO}^{*}$ & $\mathrm{MnO}$ & $\mathrm{MgO}$ & $\mathrm{CaO}$ & $\mathrm{Na}_{2} \mathrm{O}$ & $\mathrm{K}_{2} \mathrm{O}$ & $\mathrm{P}_{2} \mathrm{O}_{5}$ & $\mathrm{SO}_{2}$ & $\mathrm{~F}$ & $\mathrm{Cl}$ & $\mathrm{Cr}$ & $\begin{array}{c}\text { Total } \\
\text { oxides }\end{array}$ \\
\hline \multirow[t]{10}{*}{ Lab 1} & 74.36 & - & 12.94 & 1.46 & 0.05 & 0.06 & 0.75 & 3.94 & 5.10 & - & - & - & - & - & 98.66 \\
\hline & 74.55 & - & 12.93 & 1.54 & 0.04 & 0.05 & 0.77 & 3.88 & 5.12 & - & - & - & - & - & 98.88 \\
\hline & 74.40 & - & 12.93 & 1.52 & 0.07 & 0.05 & 0.75 & 3.97 & 5.05 & - & - & - & - & - & 98.74 \\
\hline & 74.49 & - & 12.86 & 1.51 & 0.05 & 0.04 & 0.70 & 3.92 & 5.19 & - & - & - & - & - & 98.76 \\
\hline & 74.39 & - & 12.91 & 1.47 & 0.09 & 0.05 & 0.75 & 4.00 & 5.16 & - & - & - & - & - & 98.82 \\
\hline & 74.25 & - & 12.91 & 1.58 & 0.07 & 0.05 & 0.73 & 4.04 & 5.15 & - & - & - & - & - & 98.78 \\
\hline & 74.13 & - & 12.87 & 1.53 & 0.09 & 0.04 & 0.75 & 3.94 & 5.02 & - & - & - & - & - & 98.37 \\
\hline & 74.01 & - & 12.80 & 1.57 & 0.07 & 0.07 & 0.73 & 3.97 & 5.17 & - & - & - & - & - & 98.39 \\
\hline & 74.34 & - & 12.89 & 1.43 & 0.08 & 0.05 & 0.74 & 4.00 & 5.10 & - & - & - & - & - & 98.63 \\
\hline & 74.27 & - & 12.84 & 1.52 & 0.07 & 0.05 & 0.73 & 3.94 & 5.14 & - & - & - & - & - & 98.56 \\
\hline \multirow{11}{*}{ Lab 2} & 73.87 & - & 13.12 & 1.44 & 0.06 & 0.06 & 0.80 & 4.15 & 5.14 & - & - & - & - & - & 98.64 \\
\hline & 74.85 & - & 13.33 & 1.50 & 0.05 & 0.05 & 0.74 & 3.99 & 5.16 & - & - & - & - & - & 99.67 \\
\hline & 74.15 & - & 12.85 & 1.55 & 0.09 & 0.04 & 0.77 & 3.89 & 5.16 & - & - & - & - & - & 98.50 \\
\hline & 74.38 & - & 12.76 & 1.40 & 0.02 & 0.05 & 0.79 & 4.03 & 5.02 & - & - & - & - & - & 98.45 \\
\hline & 74.13 & - & 12.95 & 1.60 & 0.06 & 0.04 & 0.78 & 4.08 & 5.04 & - & - & - & - & - & 98.68 \\
\hline & 73.85 & - & 12.96 & 1.62 & 0.07 & 0.06 & 0.75 & 4.27 & 5.21 & - & - & - & - & - & 98.79 \\
\hline & 74.45 & - & 13.02 & 1.64 & 0.06 & 0.03 & 0.80 & 4.24 & 5.23 & - & - & - & - & - & 99.47 \\
\hline & 74.81 & - & 13.01 & 1.46 & 0.05 & 0.05 & 0.77 & 4.13 & 5.23 & - & - & - & - & - & 99.51 \\
\hline & 74.29 & - & 13.04 & 1.60 & 0.09 & 0.04 & 0.71 & 4.09 & 5.27 & - & - & - & - & - & 99.13 \\
\hline & 74.20 & - & 13.20 & 1.47 & 0.08 & 0.07 & 0.72 & 4.08 & 5.12 & - & - & - & - & - & 98.94 \\
\hline & 73.59 & 0.06 & 13.20 & 1.50 & 0.12 & 0.02 & 0.73 & 3.82 & 5.33 & 0.05 & - & - & - & 0.01 & 98.44 \\
\hline \multirow{10}{*}{ Lab 3} & 74.56 & 0.08 & 13.65 & 1.37 & 0.04 & 0.03 & 0.72 & 3.86 & 5.00 & 0.00 & 0.00 & 0.13 & 0.37 & - & 99.81 \\
\hline & 74.28 & 0.09 & 13.56 & 1.43 & 0.04 & 0.05 & 0.74 & 3.94 & 5.23 & 0.03 & 0.00 & 0.16 & 0.35 & - & 99.87 \\
\hline & 74.32 & 0.06 & 13.56 & 1.47 & 0.08 & 0.05 & 0.74 & 3.92 & 5.10 & 0.00 & 0.02 & 0.17 & 0.32 & - & 99.81 \\
\hline & 73.66 & 0.08 & 13.35 & 1.52 & 0.08 & 0.04 & 0.73 & 3.91 & 5.17 & 0.00 & 0.00 & 0.13 & 0.38 & - & 99.04 \\
\hline & 74.10 & 0.06 & 13.35 & 1.43 & 0.05 & 0.05 & 0.68 & 3.94 & 5.01 & 0.02 & 0.01 & 0.13 & 0.44 & - & 99.27 \\
\hline & 74.22 & 0.08 & 13.47 & 1.57 & 0.00 & 0.04 & 0.79 & 3.88 & 5.07 & 0.04 & 0.01 & 0.13 & 0.34 & - & 99.64 \\
\hline & 73.90 & 0.10 & 13.64 & 1.67 & 0.05 & 0.03 & 0.76 & 3.99 & 5.00 & 0.02 & 0.01 & 0.19 & 0.35 & - & 99.71 \\
\hline & 73.86 & 0.11 & 13.48 & 1.42 & 0.08 & 0.04 & 0.70 & 3.94 & 5.15 & 0.01 & 0.03 & 0.15 & 0.33 & - & 99.30 \\
\hline & 74.14 & 0.06 & 13.45 & 1.27 & 0.11 & 0.02 & 0.76 & 3.85 & 5.06 & 0.04 & 0.00 & 0.09 & 0.34 & - & 99.18 \\
\hline & 73.92 & 0.06 & 13.57 & 1.53 & 0.07 & 0.04 & 0.72 & 3.89 & 5.08 & 0.00 & 0.02 & 0.13 & 0.39 & - & 99.40 \\
\hline \multirow[t]{10}{*}{ Lab 4} & 74.09 & 0.00 & 13.10 & 1.33 & 0.06 & 0.03 & 0.69 & 3.83 & 5.10 & 0.01 & - & - & - & 0.03 & 98.27 \\
\hline & 74.22 & 0.10 & 13.25 & 1.48 & 0.07 & 0.05 & 0.71 & 3.82 & 5.18 & 0.00 & - & - & - & 0.00 & 98.90 \\
\hline & 74.35 & 0.06 & 13.27 & 1.45 & 0.09 & 0.05 & 0.72 & 3.84 & 5.12 & 0.01 & - & - & - & 0.00 & 98.95 \\
\hline & 74.11 & 0.11 & 13.32 & 1.41 & 0.06 & 0.05 & 0.74 & 3.85 & 5.32 & 0.00 & - & - & - & 0.01 & 98.97 \\
\hline & 73.74 & 0.15 & 13.11 & 1.49 & 0.07 & 0.03 & 0.70 & 3.77 & 5.09 & 0.01 & - & - & - & 0.00 & 98.17 \\
\hline & 73.96 & 0.06 & 13.01 & 1.51 & 0.05 & 0.05 & 0.66 & 3.79 & 5.15 & 0.07 & - & - & - & 0.02 & 98.33 \\
\hline & 74.22 & 0.12 & 13.02 & 1.50 & 0.05 & 0.04 & 0.70 & 3.83 & 5.11 & 0.02 & - & - & - & 0.00 & 98.61 \\
\hline & 74.05 & 0.11 & 13.17 & 1.38 & 0.05 & 0.03 & 0.71 & 3.81 & 5.17 & 0.01 & - & - & - & 0.01 & 98.50 \\
\hline & 74.38 & 0.09 & 12.97 & 1.57 & 0.02 & 0.05 & 0.75 & 3.73 & 5.18 & 0.01 & - & - & - & 0.01 & 98.75 \\
\hline & 74.12 & 0.14 & 13.10 & 1.53 & 0.07 & 0.03 & 0.69 & 3.88 & 5.13 & 0.02 & - & - & - & 0.02 & 98.72 \\
\hline \multirow[t]{3}{*}{ Lab 5} & 75.61 & 0.03 & 13.66 & 1.60 & 0.06 & 0.05 & 0.78 & 2.49 & 5.05 & 0.01 & 0.01 & - & 0.35 & & 99.64 \\
\hline & 75.08 & 0.07 & 13.33 & 1.56 & 0.07 & 0.03 & 0.75 & 2.24 & 5.03 & 0.02 & 0.01 & - & 0.34 & & 98.46 \\
\hline & 75.39 & 0.09 & 13.67 & 1.67 & 0.07 & 0.03 & 0.77 & 2.44 & 5.05 & 0.01 & 0.00 & - & 0.35 & & 99.45 \\
\hline Lab 6 & 73.87 & 0.08 & 12.83 & 1.53 & 0.07 & 0.05 & 0.73 & 4.19 & 5.04 & - & - & - & - & - & 98.38 \\
\hline
\end{tabular}

Notes: Laboratory identifiers listed in Table $1 . \mathrm{FeO}^{*}$ represents total iron $\left(\mathrm{Fe}^{2+}+\mathrm{Fe}^{3+}\right)$ oxide $-=$ element concentration not determined. 